\title{
Emergence of Self-Organized Symbol-Based Communication in Artificial Creatures
}

\author{
Angelo Loula ${ }^{1,2}$, Ricardo Gudwin ${ }^{1}$, Charbel Niño El-Hani ${ }^{3,4}$, and João Queiroz ${ }^{1,3,4,{ }^{*}}$ \\ angelocl@ecomp.uefs.br, gudwin@dca.fee.unicamp.br, charbel@ufba.br, queirozj@ecomp.uefs.br \\ ${ }^{1}$ Department of Computer Engineering and Industrial Automation, School of Electrical and Computer \\ Engineering, State University of Campinas (UNICAMP), Brazil. \\ ${ }^{2}$ Informatics Area, Department of Exact Sciences, State University of Feira de Santana (UEFS), Brazil. \\ ${ }^{3}$ Research Group on History, Philosophy, and Biological Sciences Teaching, Institute of Biology, Federal \\ University of Bahia, Salvador-BA, Brazil. \\ ${ }^{4}$ Graduate Studies Program on History, Philosophy, and Science Teaching, Federal University of Bahia/State \\ University of Feira de Santana, Brazil. Graduate Studies Program in Ecology and Biomonitoring, Federal \\ University of Bahia, Brazil.
}

\author{
*Corresponding author: \\ <queirozj@ecomp.uefs.br> \\ Department of General Biology, Institute of Biology, Federal University of \\ Bahia, Campus de Ondina, Ondina, Salvador-BA, Brazil. 41270-190. \\ Phones: +55 (71) 3283-6608 \\ Fax : +55 (71) 3283-6606
}

\begin{abstract}
In this paper, we describe a digital scenario where we simulated the emergence of self-organized symbol-based communication among artificial creatures inhabiting a virtual world of unpredictable predatory events. In our experiment, creatures are autonomous agents that learn symbolic relations in an unsupervised manner, with no explicit feedback, and are able to engage in dynamical and autonomous communicative interactions with other creatures, even simultaneously. In order to synthesize a behavioral ecology and infer the minimum organizational constraints for the design of our creatures, we examined the well-studied case of communication in vervet monkeys. Our results show that the creatures, assuming the role of sign users and learners, behave collectively as a complex adaptive system, where self-organized communicative interactions play a major role in the emergence of symbol-based communication. We also strive in this paper for a careful use of the theoretical concepts involved, including the concepts of symbol and emergence, and we make use of a multi-level model for explaining the emergence of symbols in semiotic systems as a basis for the interpretation of inter-level relationships in the semiotic processes we are studying.
\end{abstract}

Keywords: emergence, symbol, semiotics, communication, self-organization. 


\section{Introduction}

There have been several different experiments concerning symbol grounding and the selforganization and emergence of shared vocabularies and language in simple (real or virtual) worlds (Roy, 2005a,b; Steels, 1999, 2003; Cangelosi et al., 2002; Cangelosi \& Turner, 2002; Vogt, 2002; MacLennan, 2002, 2001; Jung \& Zelinsky, 2000; Sun, 2000; Hutchins \& Hazlehurst, 1995)(for a review of other works, see Christiansen \& Kirby (2003), Wagner et al. (2003)). Nevertheless, several questions are still left open, especially concerning the systemic processes going on, the necessary and/or sufficient conditions for symbol emergence, and the experimental assumptions and their connections with theoretical and empirical evidence. In order to contribute to some of these questions, we propose here, inspired by ethological constraints, an experiment to simulate the emergence of selforganized symbolic (predator-warning) communication among artificial creatures in a virtual world of predatory events. To build our digital ecosystem, and infer the minimum organizational constraints for the design of our creatures, we examined the well-studied case of communication in East African vervet monkeys (Cercopithecus aethiops).

We are interested in understanding the processes and conditions for symbol-based communication to emerge in a population of creatures with no previous knowledge of symbols, given that they can only rely on their own observations, but not on any explicit feedback from other creatures. In addition, creatures must deal with an elaborate world where they must control their own actions all the time and establish communicative interactions with many other creatures at the same time. Our project deals, therefore, with the self-organization and emergence of symbol-based communication between autonomous agents, situated in an environment where they can interact in various ways with each other and with entities present in this environment. Besides wandering around, viewing each other, responding to the presence of other agents and making use of available items, during the course of their interactions agents can hear and vocalize to each other, communicating in diverse situations, and often interacting simultaneously with multiple agents.

Differently from some related work (see e.g. Oliphant (1999), Hutchins \& Hazlehurst (1995), Steels (1999, 2003), Cangelosi (2001), Vogt \& Coumans (2003), Werner \& Dyer (1992)), our agents can control their actions during communicative episodes and still maintain other interactions, instead of following a fixed sequence using just one speaker and one hearer at a time, taking turns in a communicative episode where no other action is possible. Following a fixed sequence and ruling out other actions takes away the dynamics of communication engaging and the challenge of learning in such conditions, also minimizing agent's situatedness. For that reason, we say we are dealing with dynamical and autonomous communicative interactions, following the concept of autonomous agents as agents situated in an environment capable of sensing and, fundamentally, controlling their own actions to achieve their goals (see Franklin (1997), Maes (1994), Ziemke (1998)). Communication here is viewed as just another possible action. Apart from that, as we shall describe in more details later, our agents are capable of learning the relation between signs and referents in an unsupervised manner, i.e., there is no explicit feedback about the associations that are being made between the signs they are hearing and the objects they are seeing. When a sign is heard by an agent, it can associate this sign with anything it is currently seeing or may see in a few iterations ahead. And since no explicit feedback is provided, the agent relies only on statistical evidences of co-occurrences, exploited by a Hebbian associative learning mechanism. In some of the other approaches found in the literature, agents receive an explicit feedback about either the correctness (or not) of the sign-referent association used, or the actual sign that should be used or the object that should be referred to.

It is important to emphasize that the way in which computational techniques and theoretical frameworks are integrated here is original in many ways. We strive for a careful use of the theoretical concepts involved, including the concept of 'emergence', rarely defined and/or explained in an adequate manner in the sciences of complexity and 'emergent' computation (for critical commentaries, see Cariani (1989, 1991), Emmeche (1996), Emmeche (1997), Ronald et al.(1999), Bedau (2002), ElHani (2002)). We also strive for employing the concept of 'symbol' in a consistent way, by firmly grounding its treatment on Peirce's theory of signs. Furthermore, we use a multi-level model for 
explaining the emergence of symbols in semiotic systems grounded on Salthe's (1985) hierarchical structuralism as a basis for the interpretation of inter-level relationships in the semiotic processes we are studying (Queiroz \& El-Hani, 2006a,b).

Our experiment will be explained in a detailed manner in section 5, but first we will briefly describe some of the related work and highlight differences between previous researches and our experiment. In section 3, the concepts of sign, symbol, and communication as treated in the sign theory of C. S. Peirce will be briefly presented. In section 4, we will discuss the concept of emergence, particularly in relation to the emergence of semiotic processes. Section 5 will describe our computational experiment, detailing the environment and the creatures, including their cognitive architecture and communication and learning mechanisms. Results from typical simulation runs will be reported in section 6 , followed by a discussion of the results and dynamics in section 7 , from the point of view of the theoretical frameworks previously presented.

\section{Related Work}

Various experiments involving the simulation of the acquisition of referential vocabulary repertoire of utterances associated with external referents - in a community of agents have been developed. We do not intend to present an exhaustive review of all these works here; rather, we will just select a few that are representative of different approaches to study that phenomenon.

Using a population of agents controlled by recurrent neural networks, Werner and Dyer (1992) proposed a scenario where male agents, which were blind but mobile, had to meet female agents, which were able to see but not to move, in order to mate and produce offspring, which received a recombination of their neural networks weights. Females were allowed to see only males and only one male at a time, the closest one, even if more than one was within its visual field. Males could only hear one signal at a time and from the closest female. In the beginning of simulations, males moved randomly and females emitted random signals; thus, no communication was established, since no selective pressure has been present yet. Later, due to the selective pressure for better strategies, communication started to develop, and males and females co-evolved coherent signals that could be emitted by females and could guide males towards them. In this experiment, agents were situated in an environment where they were not selected directly by their communicative success, but by their behavioral success in mating; thus, communication developed as an adaptive strategy to reproduce. The learning mechanism employed relied only upon mutation and recombination of neural networks weights when new agents were created from preceding ones, and, consequently, there was no learning during the agents' lifetime.

Hutchins and Hazlehurst (1995) also simulated a population of neural networks, but selfassociative feed-forward ones, which were trained to identify and learn binary patterns and also signals coming from other networks. At each instant, two networks were chosen from a population of them to interact. One network, acting as a teacher, received an input ('visual') signal and the activation of its hidden layer (the 'verbal' signal) was sent to another network, the learner. The learner got the same 'visual' signal and was trained to produce the same signal on its output layer (as a selfassociative network) and was also trained to have the same activation pattern in the hidden layer as the teacher. Hutchins and Hazlehurst showed that the networks were able to converge to a repertoire of common 'verbal' signals to refer to 'visual' signals. In this experiment, the neural networks were not situated in any environment that they could sense or where they could take actions, and the communicative act corresponded only to the activation of a hidden layer by a 'visual' signal and to the use of this activation pattern to train another network.

In an experiment by Oliphant (1999), associative matrixes were used by individuals (agents in a population of agents) to learn and produce signals for referents ('meanings') . Each matrix maintained associative values between all possible signals and referents, which were initially zero for new individuals. Learning was conducted in an unsupervised manner (without reinforcement signal), using what Oliphant called an observational learning - the learner only observed the signaling response of the other individuals for each referent. When a new individual was created, it was allowed to learn by observing a limited number of signals produced to each possible referent, and, therefore, in each 
observing episode there was always direct access to the referent for each emitted signal. After learning, one individual was taken out of the population and a new individual joined the remaining population. There was then a learning phase, when no signal was emitted by the individual, followed by a signal-producing phase, when no learning from others occurred. Different learning mechanisms were evaluated and it was found that it was necessary not only to increase associative values for a signal observed in response to a given referent, but also to decrease the associative value of other associations with the same signal and other associations with the same referent, a lateral inhibition mechanism. As noted by Oliphant, this corresponds to a Hebbian learning scheme, the same principle we use in our creatures but with different update rules (see Section 5). Oliphant's experiment did not deal with situated or autonomous agents, since there was no environment to sense and where to act, and referents came from an abstract pre-defined set and were used only for producing signals. And each individual received only one signal and one referent at a time, but, as Oliphant commented, the most difficult part of observational learning might not be learning in itself, but observing, which was not implemented in his experiment.

Situated autonomous agents controlled by feed-forward neural networks were used by Cangelosi (2001) in an experiment with a population of individuals inhabiting a virtual world with edible and poisonous mushrooms. According to their success in eating the right kind of mushrooms, agents were selected and allowed to produce the next generation, which would receive their initial network weights altered by mutation. Input information included location and features of a mushroom along with a possible signal emitted by another agent; output included movement direction and signal to be emitted. When communication was allowed, networks were able to receive signals from each other, but this communicative interaction did not happen between individuals that were close to each other. At every step, each network (hearer) received one signal from another network (speaker), which was randomly chosen among all the signals emitted, independently of the proximity between speaker and hearer in the environment. The speaker produced a signal after receiving the features of the hearer's closest mushroom as an input, i.e., the speaker was always placed on the hearer's perspective. This entails that the networks were always receiving some signal and this signal always referred to one mushroom, the closest one to them. And, although agents were able to self-control their movements, their communicative interactions followed a pre-defined sequence with a speaker drawn out of the population to emit a signal, always referring to the same mushroom perceived by the hearer.

A well-known experiment dealing with the emergence of referential vocabulary using language games was the Talking Heads experiment conducted by Steels $(1999,2003)$. In his experiment, robotic agents were used, physically embodied in pan-tilt cameras facing a white board with various geometric shapes, and engaging into a series of communicative interplays. In each communicative episode, agents were selected from a population to play the role of a speaker and a hearer in a guessing game. The guessing game started with the speaker choosing a topic to refer to and emitting an utterance to the hearer. Then, the hearer had to guess what the speaker was referring to and point at it. The game was successful if the hearer guessed correctly and both hearer and speaker received this feedback information about the game success and both used it as a reinforcement signal to adjust their associative memory of utterance-referent pairs. Moreover, the hearer also received additional information at the end about which topic the speaker initially chose. In this experiment, agents were not able to control most of their actions; they could select the topic, point at it and emit signals, but they must follow a pre-defined sequence for the language game script. Therefore, we can say that these agents have limited autonomy, since they cannot control their actions, and they are hardly situated, since they just sense the environment and only act in communicative tasks.

Investigating how different approaches to communicative interactions affect the acquisition of utterances-referent association, Vogt and Coumans (2003) presented three scenarios for language games between a speaker and a hearer: the observational game, in which joint attention was established and only one possible referent was present, so that there was no ambiguity about what the speaker was referring to; the guessing game, similar to that one developed by Steels, where different referents were present, but a feedback was provided regarding whether the hearer guessed the referent correctly or not; and the 'selfish' game, in which, given a set of possible referents, the speaker produced an utterance referring to one of them, but the hearer was not aware of it and had to guess 
what the referent was, with no feedback regarding the correctness of its guess. The first language game greatly simplifies the learning task, since there is only one utterance and one referent, and, although in the second game several referents are present, at the end the hearer is informed about what the topic was. The third scenario, the 'selfish' game, is the hardest one, because the hearer never knows what the referent really is and relies only upon the joint occurrence or not of utterances and referents. Vogt and Coumans suggested that a learning strategy to achieve success in this game would be that of a Bayesian learner, which computes the probability of expecting a referent given an utterance, or $P$ (referent|utterance). This learning mechanism was implemented using the same formula employed by Smith (2001): given an utterance $u$ and a referent $r$, their associative value is the ratio between the number of times $u$ and $r$ appears together divided by the total number of times $u$ appears. In their simulations, the selfish game showed the worst performance, what was expected, since it was the hardest game due to the lack of feedback. In previous experiments, Vogt (2001) reported that the selfish game was a lot worser, and could not bootstrap the formation of utterance-referent associations. Vogt and Coumans (2003) attributed that result to the lack of contextual variability, due to the use of a very limited number (3-4) of possible referents, a situation that made the same referent appear repeatedly. Another reason we can point out is that the Bayesian learning mechanism tries to establish the probability for a given referent to be present when a certain utterance is heard. This implies that, if a referent is always present, whether or not the speaker is referring to it or not, the probability value between them will be high, even though this correlation was not desired. Following a pre-defined sequence of steps to engage in a communicative interaction, the agents in the experiments of Vogt and Coumans (2003) also lacked the ability to self-control their actions; they only interacted through language games and did not perform any non-communicative task.

Besides dealing with the emergence of referential vocabulary, several works also discuss a fundamental issue in cognitive science which is closely related to that topic, namely symbol grounding. Some of them adopt Peirce's theory of signs as a theoretical framework to conceive of semiotic processes and categories (e.g., communication, meaning, symbol) (Vogt, 2002, 2003; Cangelosi et al., 2002; Jung \& Zelinsky, 2000; Roy, 2005a,b). Here, we apply Peirce's theory to define the entities and processes which we intended to simulate in our experiment - communication, sign, symbol, meaning -, thus serving as a theoretical constraint on the experiment conception besides providing a way to identify the phenomena of interest happening during simulations. In the next section, we will briefly present concepts of Peirce's semiotics.

\section{Meaning and semiosis}

The semiotics of Charles S. Peirce has long been regarded as a powerful tool for the investigation of meaning processes in biological (Ribeiro et al., 2007; Queiroz \& El-Hani, 2006b; Deacon, 1997, 2003; Noble \& Davidson, 1996; Ransdell, 1977; Emmeche, 1996) and artificial systems (Sun, 2000; Vogt, 2002; Cangelosi et al., 2002; Roy, 2005a,b). According to Peirce's model, meaning processes (semioses) occur by means of an irreducible relation between three interdependent elements: object, sign (which refers to the object), and interpretant (the sign's effect on an interpreter) (Peirce, 1998, EP 2.171). ${ }^{1}$

In his "most fundamental division of signs" (Peirce, 1994, CP 2.275), Peirce identified three different classes of signs - icons, indexes, and symbols - according to the relationship established with its object. Icons stand for their objects through intrinsic similarity or resemblance; indexes require sign and object to co-exist as events, establishing a spatio-temporal physical correlation, so that an index refers to its object by virtue of being affected by that object. In contrast, a symbol refers to its object when and only when a convention, law or habit was previously acquired or learned by the interpreter. Thus, a symbolic sign differs from other signs because it relies upon an arbitrary correspondence with its object, since it neither shares a quality with the object nor is physically connected with it.

1 Following a scholarship tradition, Peirce's works will be referred to as $\mathrm{CP}$ (followed by volume and paragraph number) for quotes from The Collected Papers of Charles S. Peirce (Peirce, 1994); EP (followed by volume and page number) for quotes from The Essential Peirce (Peirce, 1998), and MS (followed by the number of the manuscript) for quotes from the Annotated Catalogue of the Papers of Charles S. Peirce (Peirce, 1967). 
Semiosis can also be pragmatically characterized as a pattern of behaviors that emerges through the intra/inter-cooperation between agents in a communicative act, involving an utterer, a sign, and an interpreter (Peirce, 1967, MS 11, MS 318). Meaning processes and communication processes are thus defined in terms of the same "basic theoretical relationships" (Ransdell, 1977, p. 157), i.e., in terms of a self-corrective process whose structure exhibits an irreducible relation between three elements. In a communication process, "[i]t is convenient to speak as if the sign originated with an utterer and determined its interpretant in the mind of an interpreter" (Peirce, 1967, MS 11), and the interpreter may become an utterer in a subsequent communication process, trying conveying the same meaning embodied in the sign, thus establishing a chain of communicative events (Peirce, 1967, MS 318). ${ }^{2}$ This pragmatic characterization of semiosis will play a particularly important role in the analysis of the experiment discussed in this paper.

\section{The meaning of emergence}

We claim that the digital scenario we developed in our experiment leads to the emergence of selforganized symbol-based communication among artificial creatures. In the context of the sciences of complexity, the concept of 'emergence' has become very popular, to the extent that these fields are often described as dealing with 'emergent computation'. But, surprisingly, little discussion is found in these fields regarding the precise meaning of the terms 'emergence', 'emergent', and so on, as several authors highlighted (Cariani, 1989, 1991; Emmeche, 1996, 1997; Ronald et al., 1999; Bedau, 2002; El-Hani, 2002). We intend to use the idea of emergence in a precise way in this paper. For this purpose, we will employ an analysis of emergentist ideas as applied to semiotics put forward by Queiroz \& El-Hani (2006a) and extend their proposed model for the emergence of semiotic processes to the domain of symbol-based communication.

Emergent properties or processes constitute a class of higher-level properties or processes related to the microstructure of a class of systems. ${ }^{3}$ It is part of the task of an emergence theory to provide an account of which systemic properties or processes of a class of systems are to be regarded as 'emergent' and offer an explanation about how they relate to the microstructure of such systems. Accordingly, the following set of questions should be initially answered in order to apply the concept of emergence to an understanding of symbol-based communication: (i) which systems are capable of symbolic communication? (ii) How can we describe levels in such systems? (iii) Can symbol-based communication be described as a systemic process?

Symbol-based communication is a kind of semiotic process, and, thus, the first constraint for a system capable of such communication is that it should be a semiotic system. A semiotic system is a system that produces, communicates, receives, computes, and interprets signs of different kinds (Fetzer, 1988, 1997). Its behavior is causally affected by the presence of signs, which make it possible, when interpreted, that the system adjusts its behavior to its circumstances, due to the fact that signs stand for something else iconically, indexically, or symbolically, for that system (Fetzer, 1997, p.358). This kind of system is capable of symbol-based communication when the interpreters and utterers are capable of handling signs that relate with their objects by means of a convention, law or habit previously acquired or learned by the system.

2 Those familiar with Peircean semiotics might notice that communicative chains are formed somewhat differently from the S-O-I chains, where chains are formed when interpretants turn into signs. Nevertheless, this issue does not fall into the scope of this paper and will be addressed only in future works.

The reason why such a broad statement, with its open clauses, is more adequate for explaining what is an emergent property or process in a general sense than a definition with more content and precision has to do with the fact that the concept of emergence and its derivatives are employed in the most diverse fields, and, consequently, a more detailed definition is likely to apply to some fields but not to others. It is true, however, that a more concrete and operational definition is needed when one is dealing with particular cases of emergence. The basic idea is not that one should rest content with such a general, broad statement, but, rather, that attempts to made it more precise should be dealt with case by case, considering specific theoretical and empirical constraints on the meaning of 'emergence' in different research fields. When one intends to build an emergentist account of semiotic processes, it is necessary to develop further the main ideas involved in treating those processes as 'emergent', as Queiroz and El-Hani (2006a) do. In this section, we basically summarize the ideas developed in that paper. 
Emergence theories also require a distinction between systemic and non-systemic properties and an assumption of a hierarchy of levels of existence. Previously, we took Salthe's (Salthe, 1985) basic triadic system (Figure 1) as a ground for developing a three-levels hierarchical model for semiotic systems/processes (Queiroz \& El-Hani, 2006a,b). In this model, we consider (i) a focal level, where an entity or process we want to investigate is observed in a hierarchy of levels; (ii) a lower level, where we find the parts composing that entity or process; and (iii) a higher level, into which the entities or processes observed at the focal level are embedded. Both the lower and the higher levels have constraining influences over the dynamics of the processes at the focal level. The emergence of processes (e.g., symbol-based communication) at the focal level can be explained by means of the interaction between these higher- and lower-level constraints so as to generate its dynamics. At the lower level, the constraining conditions amount to the possibilities or initiating conditions for the emergent process, while constraints at the higher level are related to the role of a selective environment played by the entities at this level, establishing boundary conditions that coordinate or regulate the dynamics at the focal level.

\begin{tabular}{|c|c|}
\hline $\begin{array}{c}\text { macro-level } \\
\text { boundary conditions }\end{array}$ & $\begin{array}{l}\text { network of communication processes } \\
\text { (semiotic environment, context) }\end{array}$ \\
\hline potentialities $\uparrow \downarrow$ selection & potentialities $\uparrow \downarrow$ selection \\
\hline $\begin{array}{l}\text { focal-level } \\
\text { observed processes }\end{array}$ & $\begin{array}{l}\text { communication events } \\
\text { (utterer-sign-interpreter relation) }\end{array}$ \\
\hline potentialities $\uparrow \downarrow$ selection & potentialities $\uparrow \downarrow$ selection \\
\hline $\begin{array}{l}\text { micro-level } \\
\text { initiating conditions }\end{array}$ & relations of determination within S-O-I \\
\hline
\end{tabular}

Figure 1: A scheme of the determinative relationships in Salthe's basic triadic system as we interpret them. The focal level is not only constrained by boundary conditions established by the higher level, but also establishes potentialities for constituting the latter. In turn, when the focal level is constituted from potentialities established by the lower level, a selection process is also taking place, since among those potentialities some will be selected in order to constitute a given focal-level process.

Semiotic processes at the focal level are described here as communication events. We address the interaction between semiosis at the focal level, potential determinative relations between elements at the lower level (micro-semiotic level) and networks of semiotic processes at the higher level (macro-semiotic level). Accordingly, what emerges at the focal level is the product of an interaction between processes taking place at lower and higher levels, i.e., between the relations within each S-OI triad established by an individual utterer or interpreter and the embedment of each individual communicative event, involving an utterer, a sign and an interpreter, in a whole network of communication processes corresponding to a semiotic environment or context. ${ }^{4}$

The macro-semiotic (or higher) level regulates the behavior of potential S-O-I relations; it establishes the patterns of interpretive behavior that will be actualized by an interpreter, among the possible patterns it might elicit when exposed to specific signs, and the patterns of uttering behavior

4 The use of the term 'context' here as something corresponding to a network of communicative events is close to the sense of 'context' in Pragmatics, which sees language use in a given context, relating many dimensions such as social, linguistic and epistemic ones. The 'physical context' of Pragmatics, however, will be better described below as 'physical contextual constraints'. 
that will be actualized by an utterer, among the possible patterns it might elicit when vocalizing about specific objects. This macro-semiotic level is composed of a whole network of communicative events that already occurred, are occurring and will occur; it characterizes the past, present, and future history of semiotic interactions, where utterers are related to one or more interpreters mediated by communicated signs, interpreters are related to one or more utterers, and interpreters turn into utterers.

We can talk about a micro-semiotic (or lower) level when we refer to a repertoire of potential sign, object, and interpretant relations available to each interpreter or utterer, which might be involved in interpreting or uttering processes. Thus, in the micro-semiotic level we structurally describe the sign production and interpretation processes going on for an individual involved in a communicative act and, therefore, we talk about S-O-I triads instead of sign-utterer-interpreter relations. When an utterer, mediated by a sign, is connected to an interpreter, and thus a communication process is established, we can talk about a focal level, which necessarily involves individual S-O-I triads being effectively formed by utterer and interpreter. But in a communicative event, the actualization of a triad depends on the repertoire of potential sign, object, and interpretant relations and also on a macro-semiotic level, i.e., to networks of communication processes, which defines a context for communicative processes establishing boundary conditions that restrict the actualization from possibilities (for more details, see Queiroz \& El-Hani (2006a,b)).As to the third question, symbol-based communication should be regarded as a systemic process because, as we just saw, the actualization of potential triads depends on boundary conditions established by a macrosemiotic level, amounting to networks of communication processes. Therefore, although symbol-based communication is instantiated, according to our model, at the focal level, it is indeed a systemic process, since the macro-semiotic level establishes the boundary conditions required for its actualization.

It is possible to recognize in the diversity of emergence theories a set of other central ideas (Stephan, 1999, chapter 3), which indicate a further set of important questions to answer in order to treat semiosis as an emergent process. Emergentists should, in a scientific spirit, accept naturalism, assuming that only natural factors play a causal role in the universe. In the current scientific picture, this implies a commitment to 'physical monism': any emergent property or process is instantiated by systems that are exclusively physically constituted. Semiotic processes are relationally extended within the spatiotemporal dimension and can only be realized through physical implementation, so that something physical has to instantiate or realize them (Emmeche, 2003; Deacon, 1999, p.2). Consequently, any semiotic system, including those capable of handling symbols, should be physically embodied.

Emergentist thinking is also characterized by a fundamental commitment to the notion of novelty, i.e., the idea that new systems, structures, entities, properties, processes, and dispositions appear in the course of the evolution. We adopt here an epigenesis view about the origin of systems capable of producing, communicating, receiving, computing, and interpreting signs. We assume that, before the emergence of semiotic systems, only non-semiotic systems existed, which were not capable of using signs, i.e., of taking something as standing for something else. Within this set of assumptions, we can say that semiotic systems constitute a new class of systems, with a new kind of structure, capable of producing and interpreting signs, and, thus, of realizing semiosis (meaning process), as an emergent process.

Another characteristic of physicalist emergence theories is the thesis of synchronic determination, a corollary of physical monism: A system's properties and behavioral dispositions depend on its microstructure, i.e., on its parts' properties and arrangement; there can be no difference in systemic properties and dispositions without there being some difference in the properties of the system's parts and/or in their arrangement. To examine the idea of synchronic determination, we have to focus our attention on the relationship between communicative events, at the focal level, and individual (potential) S-O-I triads, at the micro-semiotic level. It is clear, from the Peircean framework, that all kinds of meaning processes (semioses), including symbol-based communication, are synchronically determined by the microstructure of the individual triads composing it, i.e., by the relational properties and arrangement of the elements $\mathrm{S}, \mathrm{O}$, and I.

The ideas mentioned above are sufficient for the proposal of an emergence theory compatible 
with reductionist accounts. Emergentists, however, usually aim at non-reductionist positions, which demand additional claims, such as those of irreducibility.

Stephan $(1998,1999)$ distinguishes between two kinds of irreducibility. The first is based on the behavioral unanalyzability of systemic properties, i.e., on the thesis that systemic properties that cannot be analyzed in terms of the behavior of the parts of a system are necessarily irreducible. A second notion concerns the non-deducibility of the behavior of the system's parts. In these terms, a systemic property will be irreducible if it depends on the specific behavior the components show in a system of a given kind, and this behavior, in turn, does not follow from the components' behavior in isolation or in other (simpler) kinds of system. Semiotic processes are regarded by Peirce as irreducible in the sense that they are not decomposable into any simpler relation. Therefore, we can assert that Peirce is committed to irreducibility in the sense of non-deducibility: The specific behavior of the elements of a triad is irreducible because it does not follow from the elements' behaviors in simpler relations (i.e., monadic or dyadic relations), and, consequently, any property or process realized (synchronically determined) by those elements will be similarly irreducible.

Before proceeding, we should also distinguish emergent processes from self-organizing processes. Self-organizing systems typically exhibit emergent properties or processes; thus, selforganization describes a possible dynamics in emergent processes, but not the only one for emergence. Self-organizing systems establish a growing order (redundancy, coherence) based on local interactions between its components, without any external or central control of this process. Positive and negative feedbacks play an important role in self-organizing systems, allowing them to exploit and explore order patterns. Local interactions determine circular relations between components, as they mutually affect each other's states. Self-organization is one possible dynamics going on in a system for emergence to occur and this is what takes place, as we will explain later, in our experiment.

We hope the conditions that should be fulfilled for symbol-based communication to be characterized as an emergent process in semiotic systems were made clear in this section, contributing to a more precise account of the emergence of this kind of semiotic process in the context of the simulations implemented in the research reported here.

\section{Simulating Symbolic Creatures}

In building the experimental setup, we also considered further constraints following from biological motivations, inspired by ethological case studies of intra-specific communication for predator warning (e.g. Griesser \& Ekman, 2004; Proctor, Broom, \& Ruxtona, 2001; Manser, Seyfarth, $\&$ Cheney, 2002). More specifically, we examined alarm calls from vervet monkeys. These primates possess a sophisticated repertoire of vocal signs that are used for intra-specific social interactions, as well as for general alarm purposes regarding imminent predation on the (Seyfarth, Cheney, \& Marler, 1980). Field studies (Seyfarth et al., 1980) revealed three main kinds of alarm calls which are used to warn about the presence of (a) terrestrial stalking predators such as leopards, (b) aerial raptors such as eagles, and (c) ground predators such as snakes. When a "leopard" call is uttered, vervets escape to the top of nearby trees; "eagle" calls cause vervets to hide under trees; and "snake" calls elicit rearing on the hindpaws and careful scrutiny of the surrounding terrain. Playback experiments produced evidences that referential properties might be involved, and, thus, that symbols might be present in this communication case (Queiroz and Ribeiro, 2002; Ribeiro et al., 2007).

Empirical research about the vervet monkey alarm-call system revealed in particular that infantile and young adult vervets do not have the competence of either interpreting or emitting these calls efficiently (Cheney \& Seyfarth, 1990). Learning is involved in vocal production, in use of calls for specific events and in response to calls. Infant vervets already babble alarms for broad and mutually exclusive categories like 'flying birds', but they are unable to recognize whether the birds are predators of their group or not (Seyfarth \& Cheney, 1986). Although vervet monkeys appear to have an innate predisposition to vocalize calls which are similar to alarm calls for predator-like objects, they have to learn to recognize and respond to those calls (Cheney \& Seyfarth, 1998). Besides the assumption that the mapping between calls and predators can be learned is also supported by the observation that cross-fostered macaques, although unable to modify their call production, "did learn 
to recognize and respond to their adoptive mothers' calls, and vice versa" (Cheney \& Seyfarth, 1998). In our experiment, we assume that an associative learning competence is used for the acquisition and response to all alarm calls.

The well-studied case of communication for predator warning in vervet monkeys inspired the creatures' design and the ecological conditions in our experiment. Our creatures are autonomous agents inhabiting a virtual bi-dimensional environment (figure 3). The environment is the place where the agents interact with one another and with things present in the virtual world. As part of a project on artificial life, we are simulating an ecosystem that allows agents' cooperative interaction, including intra-specific communication by alarm calls to alert about the presence of predators.

The virtual world is composed of creatures divided into preys and predators (terrestrial, aerial, and ground predators), and also of things such as trees (climbable objects) and bushes (used to hide). We have previously proposed two different roles for preys: teachers (sign vocalizers) and learners (sign apprentices), both inhabiting and interacting within the same environment, but with teachers emitting pre-defined alarms for predators and learners trying to find out without explicit feedback which predators each alarm is associated with (Loula et al., 2004a,b). In the present paper, we ask what would happen if there were no previous alarm calls and the creatures needed to create their own repertoire of alarms. We introduce a special type of prey, which is able to create alarms, vocalize them to other preys, and learn from other preys, even simultaneously. We designed these creatures without any pre-defined alarm-predator associations that could be initially used, attempting to demonstrate how a simple learning mechanism might make it possible to acquire those associations. These preys are called here self-organizers ${ }^{5}$, because each prey learns the sign it hears and uses them in future interactions, permitting a circular relation to happen: the effect preys have on one another is also the cause of this effect, because sign learning depends on sign usage, which in turn depends on sign learning. The aim of the experiment was to investigate a potentially self-organizing dynamics of signs, in which, starting with no specific signs to predators, symbol-based communication can emerge with convergence to a common repertoire of symbol-based alarm calls, via local communicative interactions.

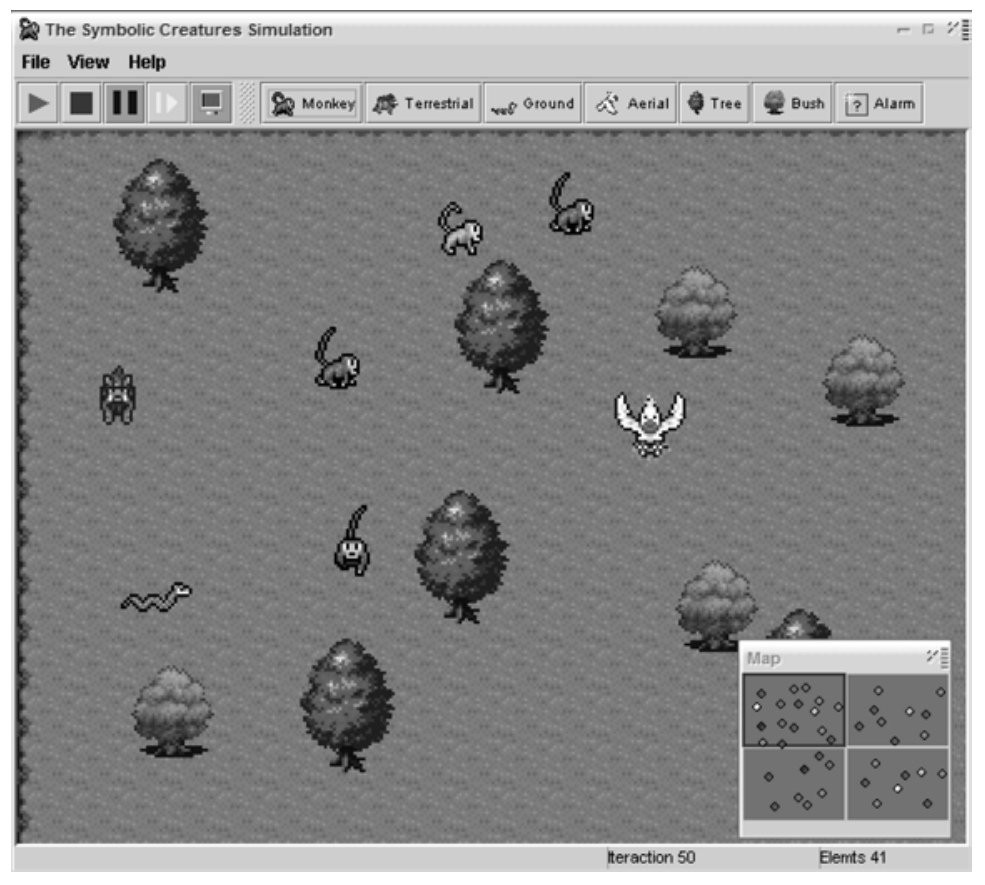

5 This experiment about the self-organization of referential vocabulary is inspired by related works, such as Steels (1999, 2000), Cangelosi (2001), Hutchins \& Hazlehurst (1995). 
Figure 3: The Symbolic Creatures Simulation, used to simulate the creatures' interactions (for further technical details, check

http://www.dca.fee.unicamp.br/projects/artcog/symbcreatures).

The creatures have sensors and motor abilities that allow their interaction with the virtual environment. The sensorial modalities found in the preys include hearing and seeing, and each prey has parameters that determine its sensory capabilities, such as range, aperture, and direction. For the sake of simplicity, predators can see but not hear. Visual perception is also simplified and there is no visual data categorization, i.e., creatures perceive directly what kind of item they are seeing: a tree, a bush, a prey, or any of the three predators. The creatures also have interactive abilities defined by a set of possible individual actions - adjustment of sensors, movement, attack, climb on tree, hide under bush, and vocalize alarms. The last three actions are specific for preys, while attacks are specific for predators. To perform the connection between sensors and actuators, the creatures need an artificial mind, which is seen as 'control structures for autonomous agents' (Franklin, 1995). Both preys and predators are controlled by an architecture inspired by behavior-based approach (Brooks, 1990; Mataric, 1998) and dedicated to action selection (Franklin, 1997). This architecture allows the creature to choose between different conflicting actions, given the state of the environment and the internal state of the creature. We will briefly describe the control architecture for predators and preys, and concentrate in describing the associative learning mechanism. Further details can be found in Loula et al. (2004a) and in the website referred in Figure 3.

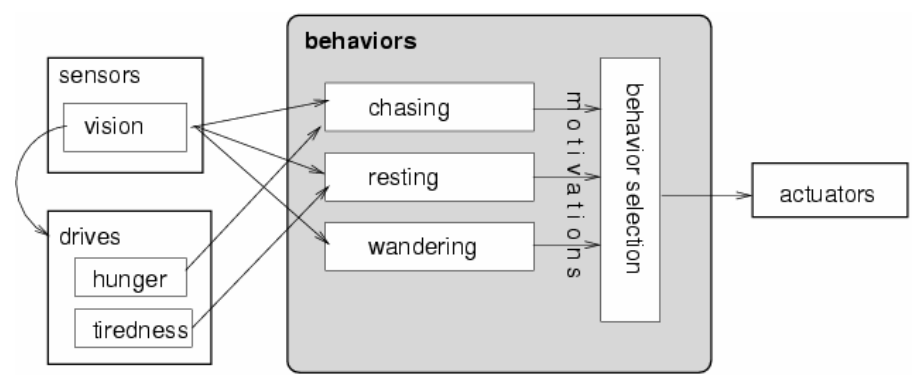

(a)

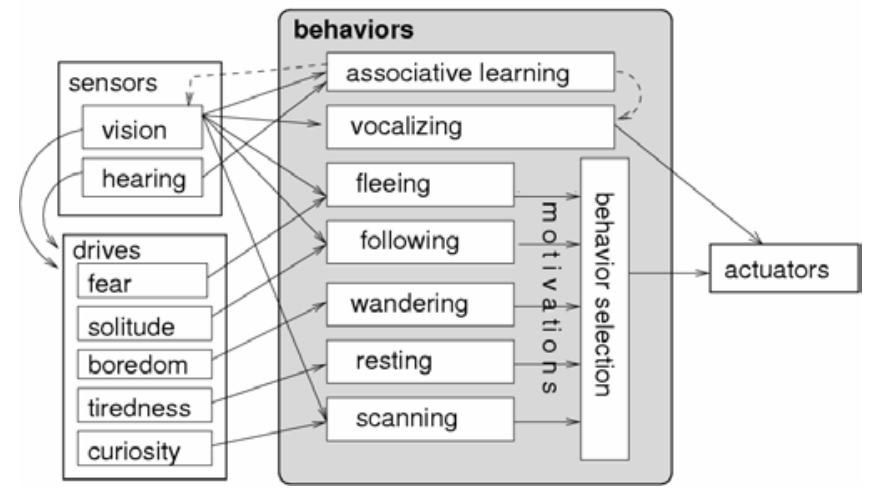

(b)

Figure 4: Predators' (a) and preys' (b) control architectures: behaviors, motivations and drives. The associative learning behavior in preys affects the associative memory and therefore the vocalizing behavior may alter, concerning the signs which are vocalized, and other behaviors may also be affected as if an alarm associated predator was seen (dashed lines, b).

The control mechanism used by the creatures is composed of behaviors, drives and motivations (figure 4). Each behavior is an independent module that competes to be the active one and control the creature. The drives define basic instincts or needs such as fear or hunger, and are represented by numerical values, updated at each instant based on external stimuli or time passing. Based on the 
sensorial data and creature's internal drives, a motivation value is calculated for each behavior, which is used in the behavior selection process. The behavior with the highest motivation value is selected to control the creature. This mechanism is not learned but rather designed, being simple to implement and yet having a rich dynamics, enabling the creatures to act in a variety of ways.

In every iteration, visual and hearing stimuli are determined (depending on sensorial range and location of every item in the environment) for each creature and sent to their control architecture that will use it to update drives and behaviors. The motivation value for each behavior is determined and the one with the highest value is selected to define the actions that will be carried out. The actions are executed and a new iteration starts.

The predators have a simple control architecture that only tries to resolve the action selection problem (figure 4a). It has three basic behaviors - wandering, prey chasing, and resting - and two drives - hunger and tiredness. The preys are the central elements of the experiment, since they are the ones involved in communicative acts, vocalizing, interpreting and learning alarms. Among the preys' behaviors, the communication-related behaviors are the ones that provide the preys with the ability to engage in communicative acts (figure 4b). Such behaviors are vocalizing, (visual) scanning, following, and associative learning. And besides communicating, the preys should also have other tasks to perform (basic behaviors) in order to keep them busy even when not communicating: wandering, fleeing, and resting. Related to all these behaviors, the preys have different drives: boredom, tiredness, fear, solitude, and curiosity. ${ }^{6}$

The behavior of 'following' makes the preys stay together trying to follow each other, allowing communicative interaction to happen more often, since it makes it more likely that there will be a prey around to hear an alarm emitted by another one. When a prey hears an alarm, the scanning behavior is usually activated and makes the prey direct its vision towards the alarm emitter and its surroundings, in search for possible referents for the vocalized alarm. The vocalizing behavior makes the prey produce an alarm, when it sees a predator, which can be heard by any other prey, provided the alarm call is within its hearing range. Self-organizers do not have a pre-defined repertoire of alarm-predator associations, and, thus, their vocalizing repertoire depends on the associative memory. When a predator is seen, they use the alarm with the highest association strength for that predator, or create a new alarm if none is known. Alarms are created by randomly choosing one among 100 possible (numerical) alarms that preys can emit. Running simultaneously with all other behaviors, associative learning is the most important behavior in the experiment.

As stated in section 3, symbols correspond to signs that are connected with their objects by the 'symbol-using agent', i.e. an internal association should be established to link them together, without which the sign could not be interpreted, at least not as a symbol. Associative learning allows the prey to learn temporal and spatial relations from the external stimuli and, thus, acquire association rules necessary to interpret signs as symbols. When a prey vocalizes an alarm, a nearby prey may hear it and scan the surroundings, searching for possible co-occurring events. There is an obvious association between an alarm call and the possible scanned referents at a given episode, which can be treated as indexical, but the prey must be able to find out which referents are suitable, i.e., it should generalize an association for future occurrences, and, thus, engage in symbol-based communication.

Sensorial data from vision and hearing are received by the respective work memories. The work memory is a temporary repository of sensorial stimuli: when a stimulus is received from the sensor, it is put in the work memory and kept for a few iterations, and then taken out of the work memory. This makes it possible for stimuli received in different instants to coexist for some time in the memory, preserving indexical (spatial-temporal) relations. The items in the work memory are used by the associative memory to create, reinforce or weaken associations between the items from visual work memory and hearing work memory (figure 5).

\footnotetext{
6 For further technical details about creatures control (e.g. drives, motivations, sensors, actions), see (Loula et al., 2004a).
} 


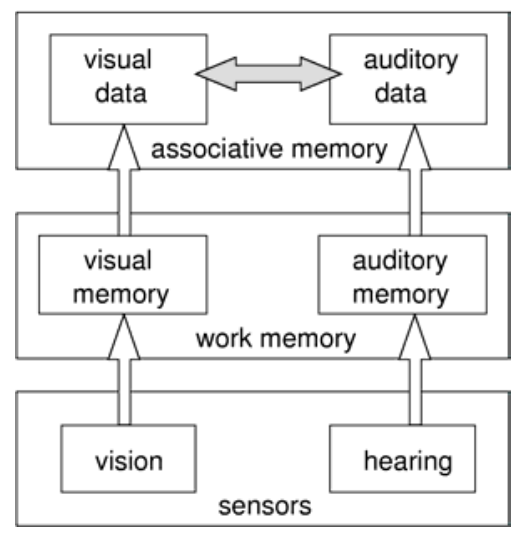

Figure 5: The associative learning modules: sensors, work memories, and an associative memory. Stimuli coming from the sensors are kept in the work memory for a few iterations and are used by the associative memory to learn the co-relations between visual and hearing stimuli.

(a)

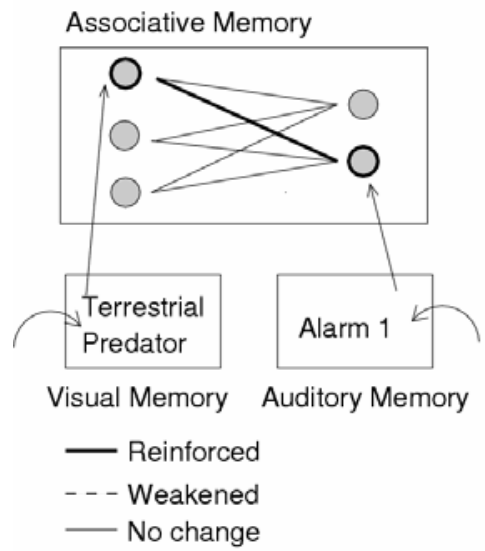

(b)

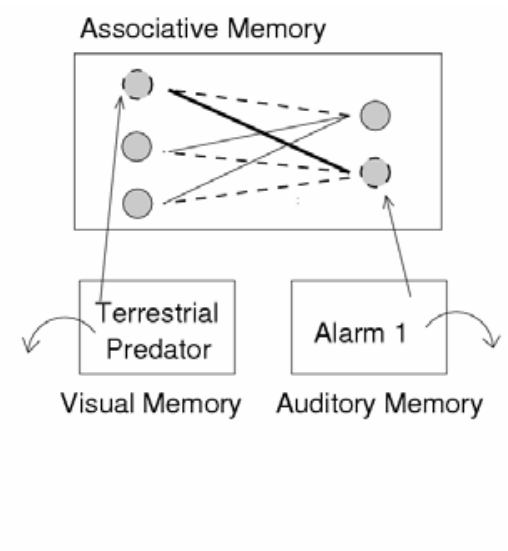

Figure 6: Reinforcement and weakening. (a) When an item is present in both of the work memories, the association between visual items and hearing items are reinforced in the associative memory and cannot be adjusted momentarily. (b) When an item leaves either of the work memories, any related association that was not reinforced is weakened. When

both items are dropped, the associations which were reinforced can be adjusted in subsequent iterations.

Following Hebbian learning principles (Hebb, 1949), when sensorial data enters the work memories, the associative memory creates, or reinforces, the association between the visual item and the hearing item, and restrains changes in this association (figure 6). Adjustment restrictions avoid multiple reinforcements in the same association caused by persisting items in the work memory. When an item is dropped from the work memory, related associations can be weakened, if changes were not restricted, i.e., if it was not already reinforced. When the two items of a reinforced association are dropped out of the work memories, the association is subject again to changes in its strength in further iterations. The positive (reinforcement) and negative (weakening) adjustment cycles in the associative memory allow preys to self-organize their repertoire, and permit common alarm-predator associations to emerge. The reinforcement and weakening adjustments for non-inhibited associations, with strengths limited to the interval $[0.0 ; 1.0]$, are done as follows ${ }^{7}$ :

7 A detail from the formulas should be explained here, the 0.01 added or subtracted will guarantee a minimal reinforcement or weakening, even if the current association is the strongest one, which would cancel out the middle term. 
- reinforcement, given a visual stimulus $i$ and a hearing stimulus $j$ in the work memories

$\operatorname{strength}_{i j}(k+1)=\operatorname{strength}_{i j}(k)+0.1\left(1.0-\left(\right.\right.$ topstrength $\left.\left._{j}(k)-\operatorname{strength}_{i j}(k)\right)\right)+0.01$

where topstrength $_{j}(k)=\max _{i} \operatorname{strength}_{i j}(k)$

- $\quad$ weakening, for a dropped visual stimuli $i$

$\forall j$ associated with $i$,

$\operatorname{strength}_{i j}(k+1)=\operatorname{strength}_{i j}(k)-0.1\left(\right.$ topstrength $\left._{j}(k)-\operatorname{strength}_{i j}(k)\right)-0.01$

- weakening, for a dropped hearing stimuli $j$

$\forall i$ associated with $j$,

$\operatorname{strength}_{i j}(k+1)=\operatorname{strength}_{i j}(k)-0.1\left(\right.$ topstrength $\left._{j}(k)-\operatorname{strength}_{i j}(k)\right)-0.01$

As stated in these equations, the reinforcement and weakening rates are variable, depending on the current strength. This makes the positive adjustment cycle stronger at each step, since the higher the strength, the higher the reinforcement is. The same goes for the negative cycle, but in the opposite direction, the lower the strength, the higher the weakening is. The changes also depend on the strongest association related to a specific hearing stimuli, and the stronger this association is, the weaker is the reinforcement of the other associations with the same stimuli. This characterizes a 'lateral inhibition' from the strongest association to the competitors and provides stability to the highest association.

The associative learning mechanism also provides a response when a vocalization associated with a predator is heard. Depending on the association strength, it can influence the creature's behavior as if the related predator was seen, and an escape response can be elicited. At first, when no association have been established yet, the prey responds indexically to an alarm call through the visual scanning behavior searching for co-occurrent events, and, thus, helping the learning process. But after the association between alarm and predator gets near maximum value, it is used to interpret the sign and an internal feedback can activate the fleeing behavior, even if a predator is not seen. Hence, at this optimum value, the prey stops scanning after an alarm is heard, and flees right away; consequently, the communicative behavior can be interpreted as a symbol-based one. Now, the interpretation of a sign (alarm), i.e., the establishment of its relation to a specific object (a predator type) depends upon an acquired habit, and not on a physical correlation between sign and object. This is an evidence that the alarm has become a symbol.

\section{Creatures in Operation}

In order to study the self-organizing and emergent dynamics in communicative acts, we performed experiments by placing together preys and predators in the environment. During the simulations, we observed the associative memory items and the behavior responses of the preys to alarm calls. Results show that there was a convergence to a common repertoire of associations between alarms and predators. This is a repertoire of symbols that make the preys engage in escape responses when an alarm is heard, even in the absence of visual cues.

Here we present results from a typical simulation run $^{8}$, using 4 self-organizers and 3 predators, together with various bushes and trees. The self-organizers can create alarms by randomly selecting one out of 100 possible alarms (from 0 to 99 ), when no alarm is known for a predator. We let the

8 Since there are random processes going on, such as the initial choice of alarms when none of them is known or unpredictable movements of the creatures due to the wandering behavior, we present only a single typical run. Nevertheless, the results presented are representative of the overall expected outcome in the experiment. 
simulation run until the community of preys converged to a common sign repertoire for the predators. Initially none of the preys have alarms associated with predators. Therefore, at the beginning of the simulation, new alarms are randomly created when they meet predators. This creates an explosion in the available alarms, that tends to be in greater number than the existing predator types. In figure 7, we see that various alarms were created to refer to each predator at first, but soon they stop appearing because every prey will know at least one alarm for each predator. Based on the observation of cooccurrence of alarms and predators, the association values are increased or decreased, but there is no guarantee that preys will always perceive this co-occurrence, e.g. an alarm is heard but the predator is out of sight. Besides, there's no explicit feedback from the vocalizing prey about whether the alarm emitted refers to a certain predator or not. 


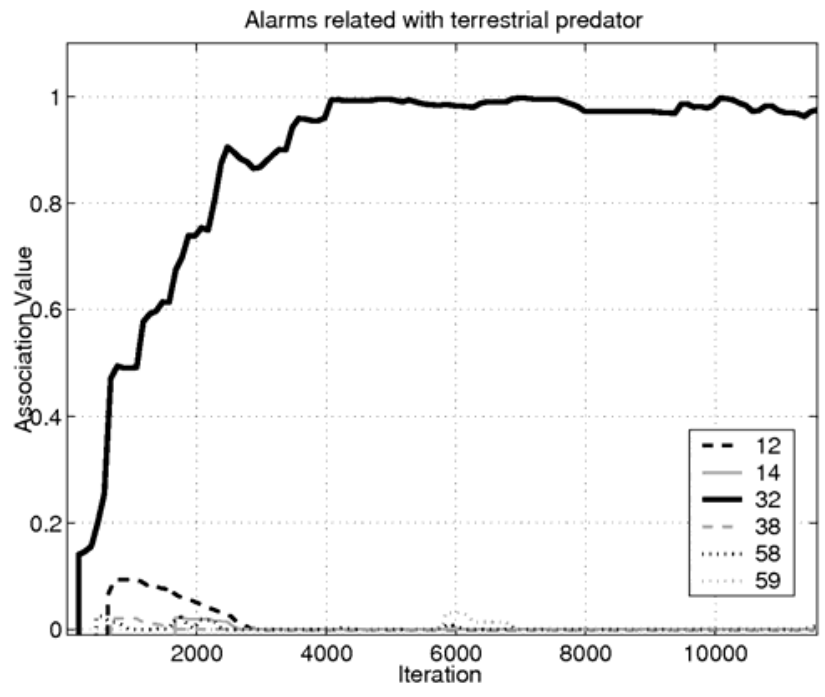

(a)

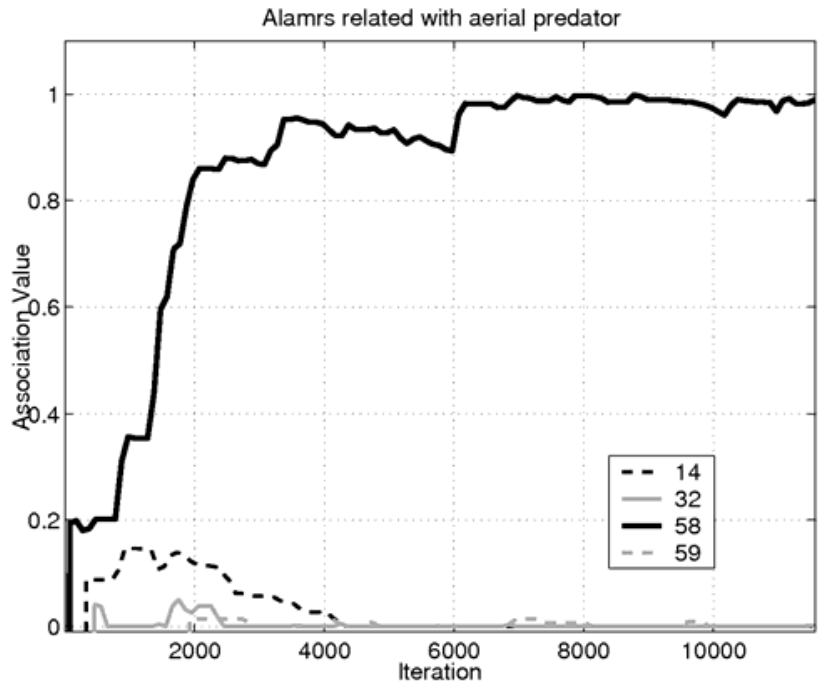

(b)

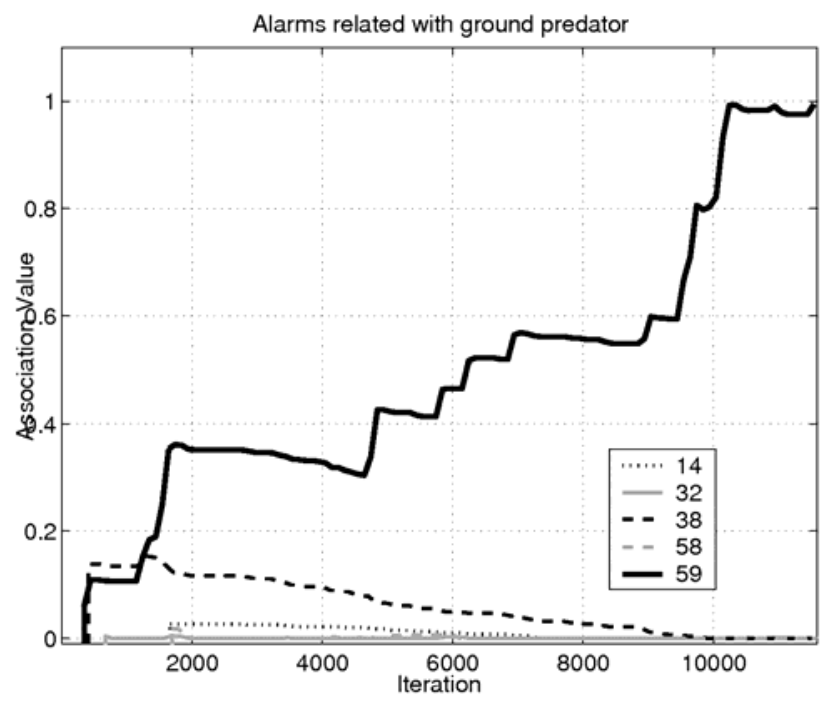

(c)

Figure 7: The mean association values of the alarm-referent associations for 4 selforganizers: (a) terrestrial predator, (b) aerial predator, (c) ground predator. Numbers in the legend represent the alarms created, used and learned by preys during a run. Alarms are also associated with other items seen, such as trees and bushes, but these associations never reach more than 0.2 during the simulation. 


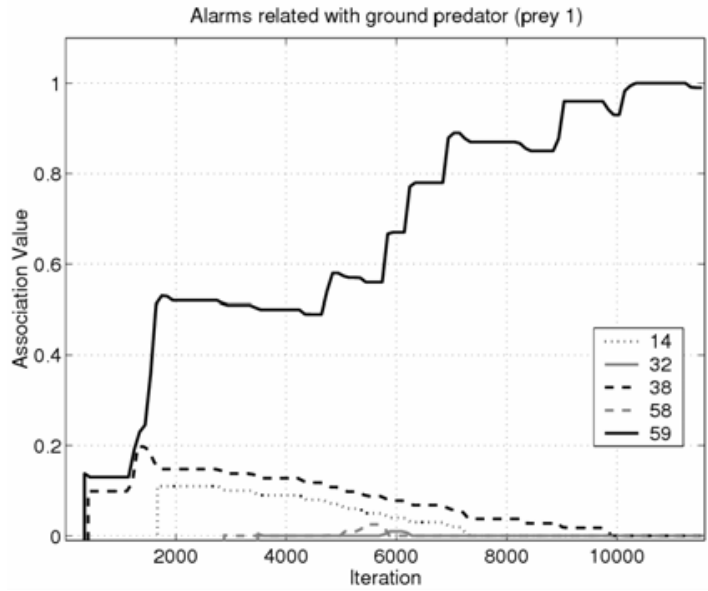

prey 1

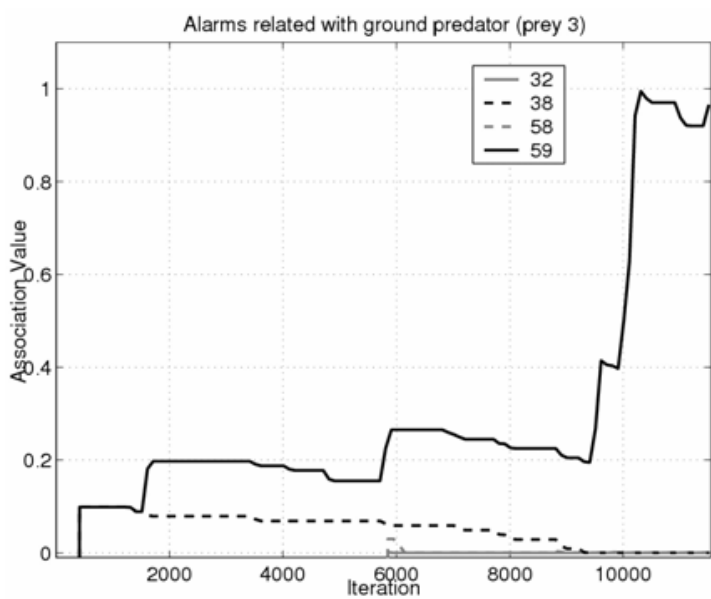

prey 3

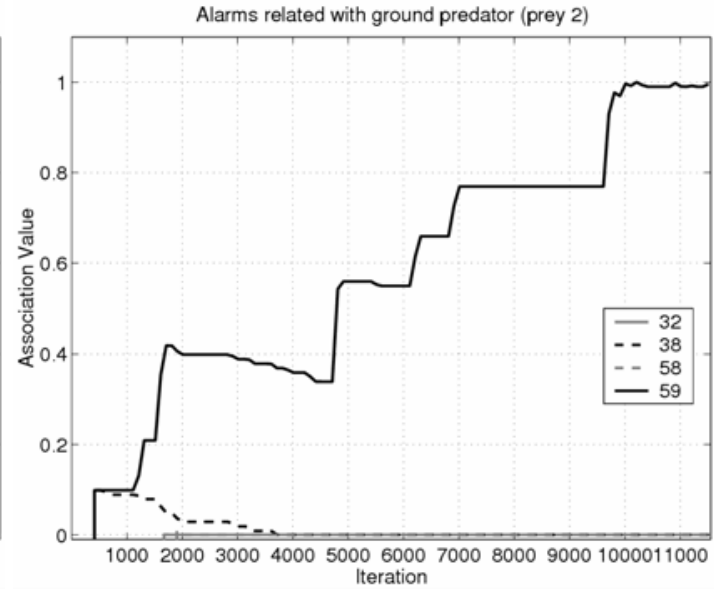

prey 2

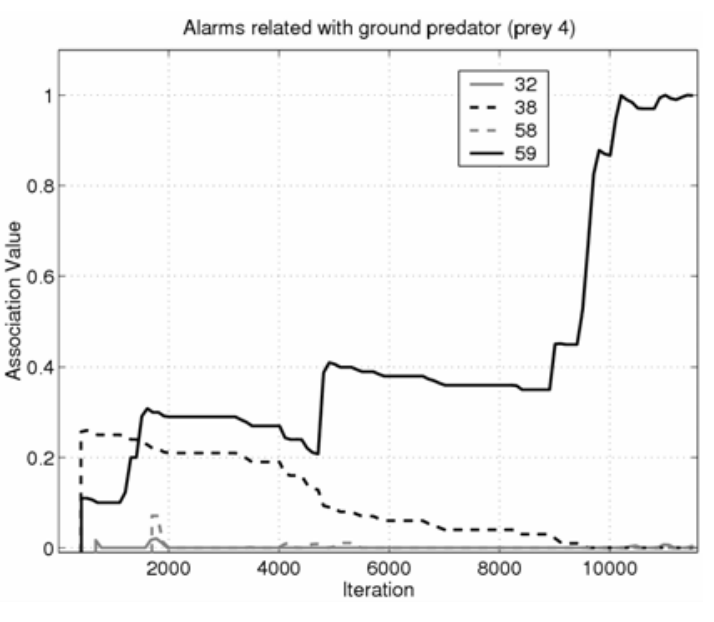

prey 4

Figure 8: The individual association values of the associations between alarms and the ground predator for the four preys.

In the graph shown in figure $7 \mathrm{a}$, the terrestrial predator is associated with alarms $12,14,32,38$, 58 , and 59, but only alarm 32 reaches the maximum value of 1.0, and the competing alarms are not able to overcome it at any time. Similar results were found in the case of alarms 14, 32, 58, and 59 associated with the aerial predator (figure $7 \mathrm{~b}$ ): only alarm 58 reached a maximum value. But among the alarms for the ground predator (figure 7c), there was a more intense competition that led to the inversion of positions between alarms 38 and 59. They were created almost at the same time in the community, and initially alarm 38 had a greater mean value than alarm 59. But between iteration 1000 and 2000, the association value of alarm 59 overcame the value of alarm 38, which slowly decayed, reaching the minimum value after iteration 9000 .

To better understand what happened in the competition between alarms 59 and 38, we present the individual graphs for each prey (figure 8). In these graphs, we see that the associations evolved in distinct ways. Alarm 59 was created by prey 1 and alarm 38 by prey 4 . Preys 2 and 3 learned these alarms, and they had similar association values before iteration 2000. But notice that prey 2 employed alarm 59 to vocalize, because it was learned first, while prey 3 preferred alarm 38 for the same reason. This led to a situation where each two preys preferred a particular alarm (38 or 59). After iteration 2000 , the frequency of usage determined the alarm success, and alarm 59 eventually overcame alarm 38. If an alarm is heard more often or before another, its chance of success is greater, because it will be reinforced more frequently or before the competing alarms. This was the reason why alarm 59 won the competition and was adopted by all preys. 


\section{Self-Organization and Emergence of Symbol-based Communication}

Together, the self-organizers constitute a complex adaptive system, with local interactions of communicative acts. By communicating, a vocalizing prey affects the sign repertoire of the hearing preys, which will adjust their own repertoire to adapt to the vocalized alarm and the context in which it is emitted. Thus, the vocalizing competence will also be affected as it relies on the learned sign associations. This implies an internal circularity among the communicative creatures, which leads to the self-organization of their repertoires (figure 9). This circularity is characterized by positive and negative feedback loops: the more a sign is used the more the creatures reinforce it (and weaken others), and, as a result, the frequency of usage of that sign increases (and others decrease); in turn, the less a sign is used the less it is reinforced, and, consequently, its usage decreases.

a)
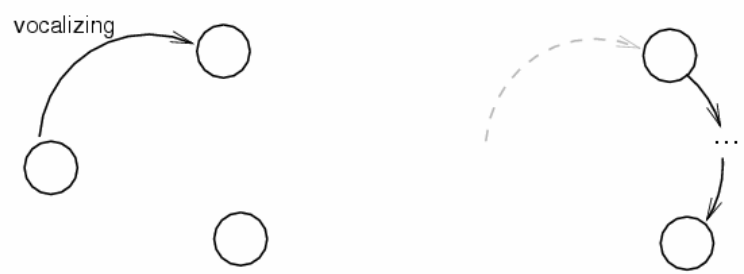

circular relations in communication

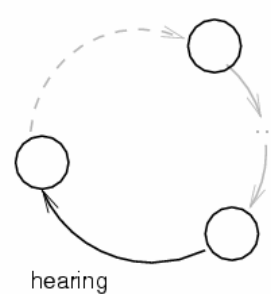

b)

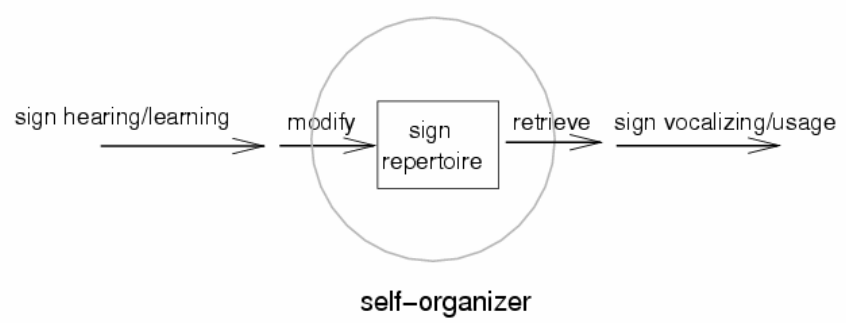

Figure 9: a) Self-organizers establish a circularity of sign usage and learning: an individual affects another one by vocalizing a sign and is affected by others when hearing a sign. The influence of an individual over others may affect it back later, and, thus, causes may be determined by effects. b) Hearing a sign induces an adjustment in an individual's sign repertoire, thus affecting also its vocalizing competence.

Moreover, as preys are both sign users and sign learners, they work as media for signs to compete, being tested every time they are used. If they are successful, i.e., if the interpreter associates the sign with the referent the utterer used it for, they will be reinforced, but if not, they will be weakened. The stronger the sign association is, the more it will be used, and the more it is used, the more it will be reinforced. This positive feedback loop allows the self-organization of the community sign repertoire, with alarm-referent associations getting stronger, making it possible that, at some point, signs become symbols.

The system can be seen as moving in a state space defined as composed of all individual sign repertoires. The system moves from point to point each time a creature adjusts its repertoire, i.e. when learning takes place. In this search space, attractors are defined as points in which all individual repertoires converge to a common one, thus stabilizing the system. When the system stabilizes, creatures will be relating predators and alarms in the same way, and vocalizing and interpreting sign in the same manner. The search in this state space, as we will describe, is constrained by boundary conditions and by initial conditions and association possibilities available.

A fundamental aspect is the presence of random perturbations ('noise') in the system dynamics, which can be amplified so as to conduct to order. These perturbations shake the system, moving it in the search space, so as to place it near a basin of an attractor (a possible common repertoire). In the absence of a previous learned sign for a predator, the prey creates one randomly, which can be adopted 
by the community or not. The creation of new random alarms introduces perturbations in the system that has its state changed, possibly closer to an attractor. Noise may also be present when a sign is heard and the creature scans its surroundings trying to establish a relation with items that it is seeing, since lots of different things can be seen, providing new relations to be established and already existing ones to have their strength changed. The presence of these perturbations also entails an unpredictability of the system's final ordered state, due to probabilistic trajectories.

In this self-organizing system, a systemic process (symbol-based communication ${ }^{9}$ ), as much as a global pattern (a common repertoire of symbols), emerges from local communicative interactions, without any external or central control. This complex system of communicative creatures can be viewed as a semiotic system of symbol-based communication with three different hierarchical levels, based on the model described in section 4.

The semiotic processes of symbol-based communication emerge at the focal level through the interaction of a micro-semiotic level, containing a repertoire of potential sign, object, and interpretant relations within an interpreter or an utterer, and a macro-semiotic level, amounting to a self-organized network of all communication processes that occurred and are occurring, involving vocalizing and hearing preys and their predators. It is in this hierarchical system that things in the environment become elements in triadic-dependent processes, i.e., alarms (signs) come to be associated with predators (objects) in such a manner that their relationship depends on the mediation of a learned association (i.e., they become symbols). In order to give a precise meaning to the idea that symbolbased communication emerges in the simulations we implemented, we argue that the semiotic processes at stake are emergent in the sense that they constitute a class of processes in which the behavior of signs, objects, and interpretants in the triadic relations actualized in communication processes cannot be deduced from their possible behaviors in simpler relations. That is, their behaviors, and, consequently, the semiotic process these behaviors realize, are irreducible due to their non-deducibility from simpler relations.

The mapping of the proposed triadic hierarchical structure onto our synthetic experiment must be further detailed in order to elucidate the dynamics and emergence of communication events. The focal level corresponds to the communicative local interactions between utterers and interpreters. As described in section 3, the Peircean sign model irreducibly relates three elements in a communication processes: sign-utterer-interpreter. More explicitly, we can talk about a vocalizing prey (the utterer) producing an alarm for a hearing prey (the interpreter), trying to transmit a warning escape alert. This communication triad can be connected to a chain of communication events, with the interpreter receiving the sign and turning into an utterer of this same meaning to another interpreter (figure 10a). This implies a possible circularity as mentioned before, when the utterer of the first episode becomes the interpreter at a future event (figure 10b). This succession of triads can become rather complicated if we notice that different utterers can communicate with the same interpreter or one utterer can vocalize to different interpreters, both simultaneously (figura 10c).

9 See section 4 for an explanation of why symbol-based communication can be treated as a systemic process. 


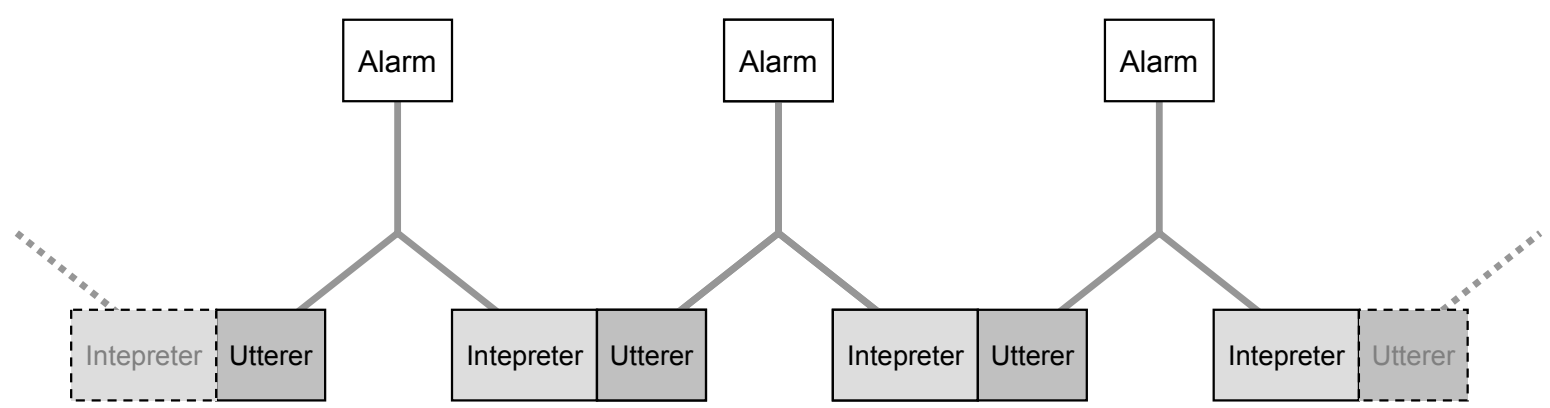

(a)

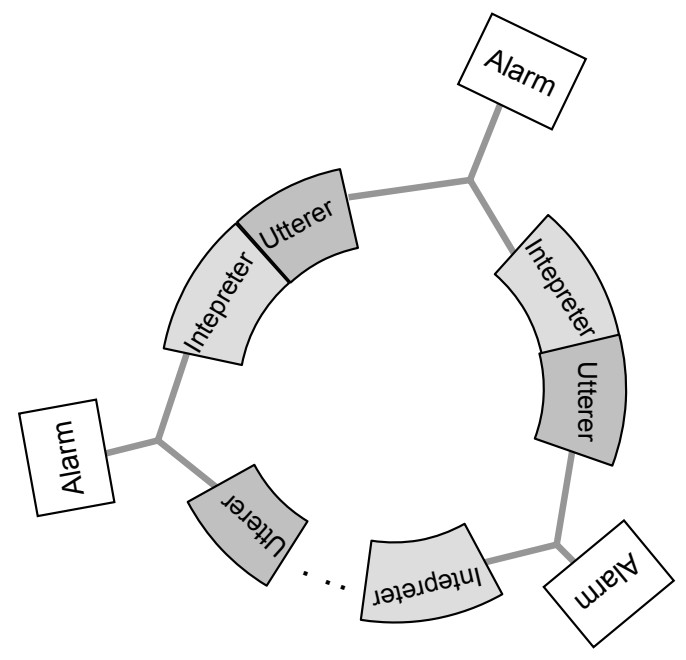

(b)
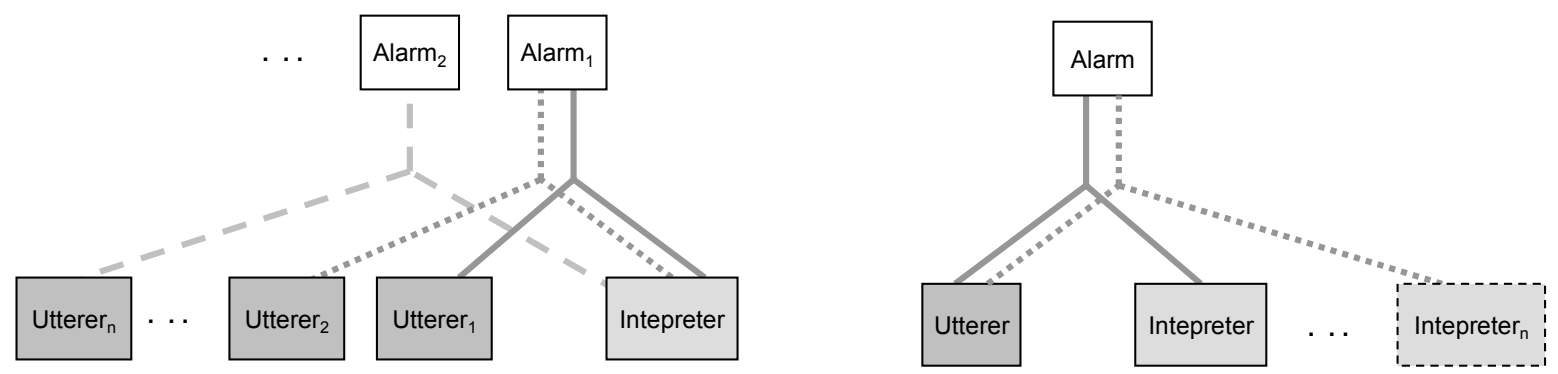

(c)

Figure 10: Communication triads involving sign-utterer-interpreter.(a) Individual triads can be connected with interpreters becoming utterers. (b) Utterers can become interpreters in future events establishing circular relations. (c) Interpreters might hear alarms from multiple utterers, and utters might vocalize to multiple interpreters, all at the same time.

This focal-level, at which communication events are actualized, is constrained by a macrosemiotic level of networks of communication triads and a micro-semiotic level of potential sign relations (figure 11) (see section 4). The micro-semiotic level establishes initiating conditions or possibilities for communication acts, since it comprises potential signs from 0 to 99 that can be related to any kind of predator by the utterer, while, in the case of the interpreter, a potential sign can be associated with any type of entity in the environment (potential object), and can elicit a variety of scanning or fleeing behaviors (potential interpretants). The environment also plays an essential role in the system dynamics by providing physical contextual constraints (visual cues). When potential sign relations are actualized, the environment in which the semiotic system is situated will establish specific constraints for the utterer's sign production (presence of predators) and for the interpreter's sign interpretation (any surrounding entity). At the macro-semiotic level, we consider focal-level 
processes as embedded into an interrelated network of chains of triads, which amounts to the system's history. This history is condensed as the communicative preys develop habits based on learning from the past communicative events, precisely located in their individual associative memories, once the associations established are a product of the past communication events and subsequent associations creation and adjustments. Hence, the system's history at the macro-semiotic level establishes constraints for the system's dynamics, which can be treated as boundary conditions, being the system variability reduced with utterers using established signs in its associative memory, and interpreters being able to use the same repository to interpret alarms, which ultimately become symbols.

At first, initiating conditions exert a stronger influence on the focal level, as triadic, semiotic relations are created on the grounds of the available potential signs, objects, and interpretants, and a macro-semiotic level is still under construction. As the system's dynamics goes on, the macrosemiotic level constrains more and more the communicative events actualized at the focal level, and, ultimately, the boundary conditions established by that level guide the system to an ordered state, which amounts to a common repertoire. At this step, symbol-based communication emerges, as a new irreducible property of the semiotic system at stake.

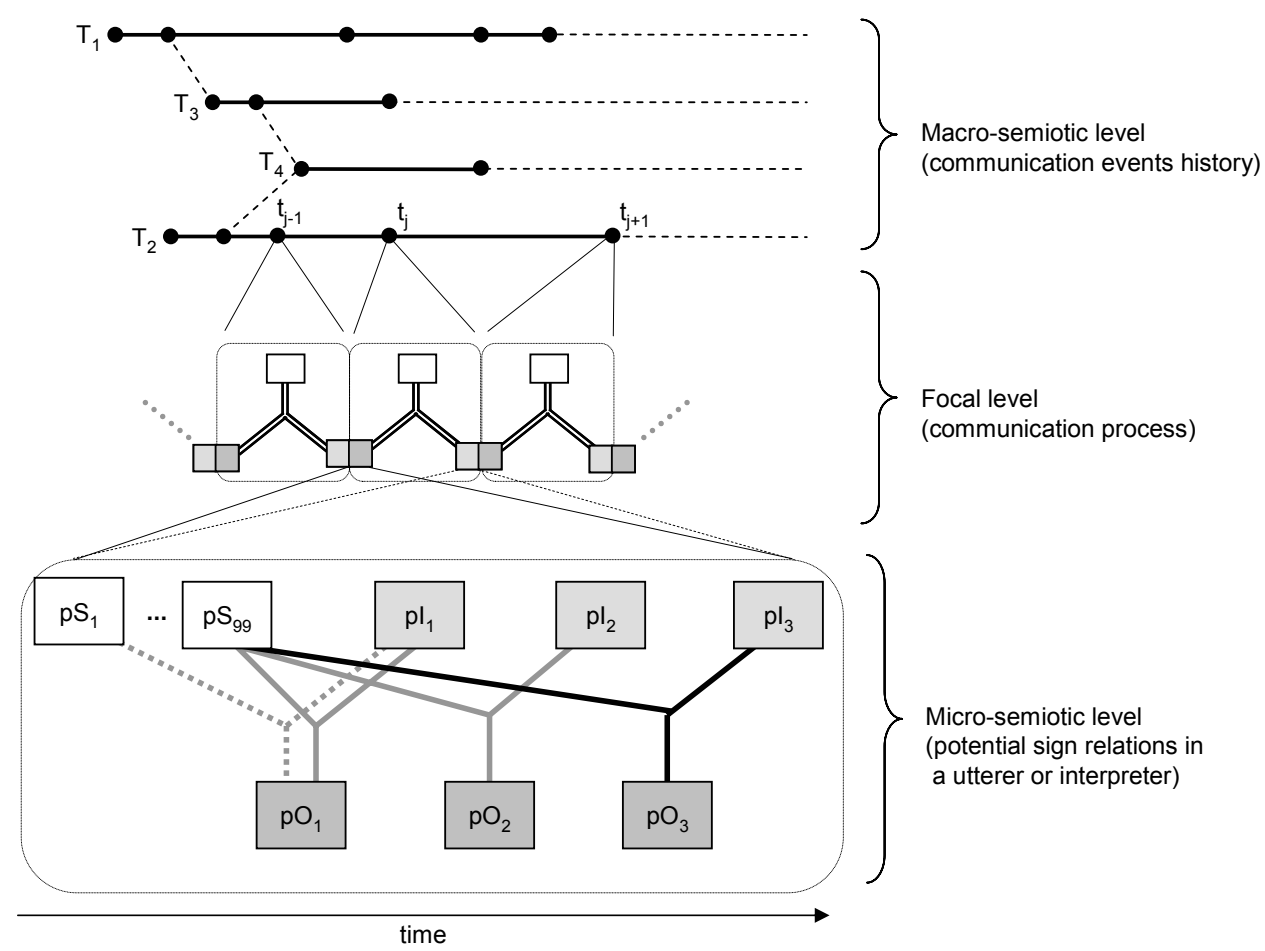

Figure 11: The triadic hierarchy of levels. Symbol-based communication emerges as focal-level semiotic processes evolve, constrained at each step by the communication processes history at the macro-semiotic level and by potential sign relations at the microsemiotic level.

$(\mathrm{pS}=$ potential sign, $\mathrm{pI}=$ potential interpretant, $\mathrm{pO}=$ potential object, $\mathrm{t}=$ single triad, $\mathrm{T}=$ sequence of triads)

\section{Conclusion}

The design and synthesis of the creatures we present here, along with the digital ecosystem, are guided by semiotic meta-principles and biological motivations. The virtual world we implemented works as a laboratory to simulate the emergence of anti-predatory alarm call vocalization among creatures under the risk of predation.

Although there have been other synthetic experiments simulating the development and evolution of sign systems, this work is one of the few to deal with multiple distributed agents performing self- 
organized autonomous communicative interactions, converging to a repertoire of symbols. We did not establish a pre-defined 'script' of what could happen in communicative acts, stating a sequence of fixed tasks to be performed by one speaker and one hearer. In our work, creatures self-govern their communication actions, they can be speakers and hearers (utterers and interpreters), vocalizing and hearing from many others at the same time, in a variety of situations. Besides, creatures learn by observing the surroundings after vocalizations are heard and do not rely on any explicit feedback from each other, i.e., no other creature is pointing to referents or evaluating associations made as correct or not.

Our experiment relies heavily on theoretical principles originated from different sources (such as Peirce's semiotics and pragmatism, emergentist philosophy, Salthe's hierarchical structuralism), which played a valuable role in assisting the development and interpretation of our experiment. On the grounds of the theoretical and empirical principles (from studies about communicative behaviors in vervet monkeys) assumed, we investigated symbol emergence from lower-level semiotic processes. Here we apply Peirce's theory of sign to the problem of the emergence of communication in artificial creatures. Moreover, we exercise care in dealing with the concept of emergence in the context of our simulations, something that unfortunately has not been as usual as it should be in the sciences of complexity.

Our multi-level model grounded on Salthe's hierarchical structuralism constitutes a formal model to study the process of the emergence of symbol-based communication. Such model allows a better understanding of this phenomenon and permits the identification of the structures and levels involved, the dynamics occurring and the adequate recognition of emergence in such semiotic systems. This constitutes thus a powerful tool to study and analyze simulations involving communication, language and other semiotic process in artificial life experiments.

The idea that a community of semiotic creatures can be understood as a complex system follows from works that view language as precisely such a kind of system (see Keller, 1994; Briscoe, 1998; Steels, 2000). Nevertheless, in our approach, viewing signs as competing entities trying to spread through a community of sign users provides a more general approach to the study of communicative interactions, since the framework we applied is not primarily committed to linguistic phenomena. The creatures behave as sign exchangers, which reproduce the learned signs, making them able to be used by other creatures, as signs disseminate in the community.

Characterized as a self-organizing system, the community of sign-manipulating individuals is seen as being formed by components interacting in a distributed manner, with emergent global properties, besides an inherent unpredictability and non-linearity. These properties make self-organizing systems hard to be studied by simply analyzing their parts separately. This suggests that a synthetic approach, in combination with an analytical one, can be an interesting strategy to study this kind of complex system, and computer simulations can have an important role in our attempts to design, model, and experiment with self-organizing systems.

Acknowledgments: The authors thank the support from CNPq, CAPES and FAPESB.

\section{References}

Bedau, M. (2002). Downward causation and autonomy of weak emergence. Principia 6 (1), 5-50.

Briscoe, T. (1998). Language as a complex adaptive system: Coevolution of language and of the language acquisition device. In Van Halteren, H. et al (Eds). Prooceedings of the 8th Meeting of Computational Linguistics in the Netherlands Conference (pp.3-40), Amsterdam..

Brooks, R.A.(1990). Elephants don't play chess. Robotics and Autonomous Systems 6, 3-15.

Cangelosi, A, \& Turner, H. (2002). L'emergere del linguaggio. In Borghi, A. M., \& Iachini, T. (Eds.) Scienze della Mente (pp.227-244). Bologna: Il Mulino. 
Cangelosi, A. (2001) Evolution of communication and language using signals, symbols, and words. IEEE Transactions on Evolutionary Computation, 5(2), 93-101.

Cangelosi, A., Greco, A., \& Harnad, S. (2002). Symbol grounding and the symbolic theft hypothesis. In Cangelosi, A. \& Parisi, D. (Eds.), Simulating the Evolution of Language (chap.9). London:Sprinter.

Cariani, P. (1989) On the Design of Devices with Emergent Semantic Functions. Ph.D. Thesis, Department of Systems Science, State University of New York at Binghamton.

Cariani, P. (1991). Emergence and Artificial Life. In Langton, C., et al. (Eds.), SFI Studies in the Sciences of Complexity, Proc. Vol. X, Artificial Life II (pp.775-797). Redwood City, CA: AddisonWesley.

Cheney, D., \& Seyfarth, R. (1990) How Monkeys See the World. Chicago and London: University of Chicago Press.

Cheney, D., \& Seyfarth, R. (1998) Why animals don't have language. In Pearson, G.B. (Ed.), The Tanner Lectures on Human Values (pp. 175-209). Salt Lake City: University of Utah Press.

Christiansen, M.H., \& Kirby, S. (2003). Language evolution: consensus and controversies. Trends in Cognitive Sciences, 7 (7), 300-307.

Deacon, T. (1997). Symbolic Species: The Co-evolution of Language and the Brain. New York: Norton.

Deacon, T. (1999). Memes as signs. The Semiotic Review of Books 10(3): 1-3.

Deacon, T. (2003). Universal grammar and semiotic constraints. In Christiansen, M.H. \& Kirby, S. (Eds.), Language Evolution (pp. 111-139). Oxford: Oxford University Press.

El-Hani, C. N. (2002). On the reality of emergents. Principia 6 (1): 51-87.

Emmeche, C. (1996). The Garden in the Machine: The Emerging Science of Artificial Life. Princeton: Princeton University Press.

Emmeche, C. (1997). Defining Life, Explaining Emergence, On-line: http://www.nbi.dk/ emmeche/ (Published in two parts as: Emmeche, C. (1997). Autopoietic Systems, Replicators, and the Search for a Meaningful Biologic Definition of Life. Ultimate Reality and Meaning 20: 244-264; Emmeche, C. (1998). Defining Life as a Semiotic Phenomenon. Cybernetics \& Human Knowing 5: 3-17).

Emmeche, C. (2003). Causal Processes, Semiosis, and Consciousness. In Seibt, J. (Ed.) Process Theories: Crossdisciplinary Studies in Dynamic Categories (pp. 313-336). Dordrecht: Kluwer.

Fetzer, J. H. (1988). Signs and Minds: An Introduction to the Theory of Semiotic Systems. In Fetzer, J.H. (Ed.) Aspects of Artificial Intelligence (pp. 133-161). Dordrecht, Netherlands: Kluwer Academic Press.

Fetzer, J. H. (1997) Thinking and Computing: Computers as Special Kinds of Signs. Minds and Machines 7, 345-364.

Franklin, S. (1995). Artificial Minds. Cambridge, MA: MIT Press.

Franklin, S. (1997). Autonomous agents as embodied AI. Cybernetics and Systems, 28(6), 499-520.

Griesser, M. \& Ekman, J. (2004) Nepotistic alarm calling in the Siberian jay, Perisoreus infaustus. Animal Behaviour, 67(5), 933-939.

Hebb, D.O. (1949) The Organization of Behavior. New York: John Wiley.

Hutchins, E., \& Hazlehurst, B. (1995). How to invent a lexicon: the development of shared symbols in interaction. In Gilbert, G. N., \& Conte, R. (Eds.) Artificial Societies: The Computer Simulation of Social Life. London: UCL Press. 
Jung, D. \& Zelinsky, A. (2000). Grounded symbolic communication between heterogeneous cooperating robots. Autonomous Robots journal, 8(3), 269-292.

Keller, R. (1994). On Language Change: the Invisible Hand in Language. London: Routledge.

Loula, A., Gudwin, R. \& Queiroz, J. (2004) Symbolic Communication in Artificial Creatures: an experiment in Artificial Life. Lecture Notes in Artificial Intelligence, 3171, 336 - 345 (Advances in Artificial Intelligence - SBIA 2004, Proceedings of the 17th Brazilian Symposium on Artificial Intelligence)

Loula, A., Gudwin, R., Ribeiro, S., Araújo, I. \& Queiroz, J. (2004). Synthetic approach to semiotic articial creatures. In Castro, L.N. \& Von Zuben, F.J. (Eds.). Recent Developments in Biologically Inspired Computing (pp. 270-300). Hersey: Idea Group Inc.

MacLennan, B. J. (2002). Synthetic ethology: a new tool for investigating animal cognition. In Bekoff, M., Allen, C., \& Burghardt, G. M. (Eds.) The Cognitive Animal: Empirical and Theoretical Perspectives on Animal Cognition (ch.20, pp.151-156). Cambridge, Mass.: MIT Press

MacLennan. B. J. (2001). The emergence of communication through synthetic evolution. In Patel, M., Honavar, V. \& Balakrishnan, K. (Eds.) Advances in the Evolutionary Synthesis of Intelligent Agents (pp. 65-90). Cambridge, Mass.: MIT Press.

Maes, P. (1994) Modeling adaptive autonomous agents. Artificial Life, 1:1-37.

Manser, M. B., Seyfarth, R. M., \& Cheney, D. L. (2002) Suricate alarm calls signal predator class and urgency. Trends in Cognitive Sciences 6(2), 55-57.

Mataric, M. (1998) Behavior-Based Robotics as a Tool for Synthesis of Artificial Behavior and Analysis of Natural Behavior. Trends in Cognitive Science 2(3), 82-87.

Noble, W., Davidson, I., (1996). Human evolution, language and mind: a psychological and archaeological enquiry. Cambridge, Cambridge University Press.

Oliphant, M. (1999) The learning barrier: Moving from innate to learned systems of communication. Adaptive Behavior, 7(3/4).

Peirce, C.S. (1967) Annotated catalogue the papers of Charles S. Peirce. Robin, R.S.(Ed.). Amherst: University of Massachusetts Press.

Peirce, C. S. (1994 [1866-1913]). The Collected Papers of Charles S. Peirce. Eletronic edition --Vols. I-VI (Hartshorne, C. \& Weiss, P. (Eds.) Cambridge: Harvard University, 1931-1935], Vols. VIIVIII (Burks, A. W. (Ed.) Cambridge: Harvard University, 1958]. Charlottesville: Intelex Corporation.

Peirce, Charles S. (1998 [1893-1913]). The Essential Peirce: selected philosophical writings. Vol. 2. Peirce Edition Project (Ed.). Bloomington: Indiana University Press.

Proctor, C.J., Broom, M., \& Ruxtona, G.D. (2001) Modelling antipredator vigilance and flight response in group foragers when warning signals are ambiguous. Journal of Theoretical Biology, 211(4), 409-417.

Queiroz, J. \& El-Hani, C. N. (2006a). Semiosis as an emergent process. Transactions of C.S.Peirce Society: A Quarterly Journal in American Philosophy 42 (1): 78-116.

Queiroz, J. \& El-Hani, C. N. (2006b). Towards a multi-level approach to the emergence of meaning processes in living systems. Acta Biotheoretica 54(3): 174-206.

Queiroz, J. \& Ribeiro, S. (2002). The biological substrate of icons, indexes, and symbols in animal communication: A neurosemiotic analysis of vervet monkey alarm calls. In Shapiro, M. (Ed.) The Peirce Seminar Papers 5 (pp.69-78). Berghahn Books, New York.

Ransdell, J. (1977). Some leading ideas of Peirce's Semiotic. Semiotica 19 (3/4), 157-178

Ribeiro, S., Loula, A., Araújo, I., Gudwin, R. and Queiroz, J. (2007) Symbols are not uniquely human. Biosystems 90(1): 263-272. 
Ronald, E.M.A., Sipper, M., \& Capcarrère, M. S. (1999). Design, observation, surprise! A test of emergence. Artificial Life, 5(3), 225-239,

Roy, D. (2005a). Grounding Words in Perception and Action: Insights from Computational Models. Trends in Cognitive Science, 9 (8): 389-96.

Roy, D. (2005b). Semiotic Schemas: A Framework for Grounding Language in the Action and Perception. Artificial Intelligence, 167 (1-2): 170-205.

Salthe, S. N. (1985). Evolving Hierarchical Systems: Their Structure and Representation. New York: Columbia University Press.

Seyfarth, R. \& Cheney, D. (1986). Vocal development in vervet monkeys. Animal Behaviour, 34: $1640-1658$.

Seyfarth, R., Cheney, D., \& Marler, P. (1980). Monkey responses to three different alarm calls: Evidence of predator classification and semantic communication. Science, 210, 801-803.

Smith, A. D. M. (2001). Establishing Communication Systems without Explicit Meaning Transmission. In Kelemen, J. \& Sosik, P. (Eds.), Proceedings of the 6th European Conference on Artificial Life, ECAL 2001 (pp. 381-390). Berlin Heidelberg: Springer-Verlag.

Steels, L. (1999). The Talking Heads Experiment: Volume I. Words and Meanings. VUB Artificial Intelligence Laboratory, Brussels, Belgium. Special pre-edition.

Steels, L. (2000) Language as a Complex Adaptive System. In Schoenauer, M. (Ed.) Proceedings of Parallel Problem Solving from Nature (PPSN) VI. Berlin, Germany: Springer-Verlag.

Steels, L. (2003). Evolving grounded communication for robots. Trends in Cognitive Sciences, 7(7), 308-312.

Stephan, A. (1998). Varieties of Emergence in Artificial and Natural Systems. Zeitschrift für Naturforschung 53c, 639-656.

Stephan, A. (1999). Emergenz: Von der Unvorhersagbarkeit zur Selbstorganisation. Dresden and München: Dresden University Press.

Sun, R. (2000). Symbol grounding: A new look at an old idea. Philosofical Psychology, 13(2), 149172.

Vogt, P. (2001) Bootstrapping grounded symbols by minimal autonomous robots. Evolution of Communication, 4(1):87--116.

Vogt, P. (2002). The physical symbol grounding problem. Cognitive Systems Research, 3(3), 429-457.

Vogt, P. (2003). Anchoring of semiotic symbols. Robotics and Autonomous Systems, 43(2). 109-120.

Vogt, P. \& Coumans, H. (2003) Investigating social interaction strategies for bootstrapping lexicon development. Journal of Artificial Societies and Social Simulation, 6(1).

Wagner, K., Reggia, J. A., Uriagereka, J., \& Wilkinson, G. S. (2003) Progress in the simulation of emergent communication and language. Adaptive Behavior, 11(1):37--69.

Werner, G. \& Dyer, M. (1992) Evolution of Communication in Artificial Organisms. In Langton, C., et al. (Eds.), SFI Studies in the Sciences of Complexity, Proc. Vol. X, Artificial Life II (pp.659-687). Redwood City, CA: Addison-Wesley.

Ziemke, T. (1998). Adaptive Behavior in Autonomous Agents. PRESENCE, 7(6), 564-587. 